\title{
O FANTÁSTICO NO GÊNERO CONTO DE TERROR'
}

\section{THE FANTASTIC IN THE GENDER TALE OF TERROR}

\author{
José Ricardo Carvalho²
}

RESUMO: O gênero de conto de terror possui regularidades enunciativas que podem ser compreendidas à luz da literatura fantástica. Para analisar contos de terror, reconhecemos a dinâmica do modo literário fantástico que explica os acontecimentos da trama sob a lógica do extraordinário ou do sobrenatural. Para Todorov (1980), o conto de terror tem o objetivo de promover o efeito de hesitação no leitor perante fatos apresentados na narrativa. Sendo assim, estudamos o modo de formulação dos contos de terror a fim de compreender os desafios que esse tipo de texto estabelece ao leitor do ponto de vista linguístico-discursivo, considerando as reflexões dos estudos literários.

PALAVRAS-CHAVE: Gênero conto de terror. Literatura fantástica. Hesitação do leitor.

ABSTRACT: The horror tale genre has enunciative regularities that can be understood in the light of fantastic literature To analyze tales of terror we recognize the dynamics of the fantastic that promotes the tension to explain and interpret the events of the plot under the logic of the extraordinary or the supernatural. For Todorov (1980), the tale of terror aims to promote the effect of hesitation in the reader in the face of facts presented by the author. Therefore, we studied the way of formulating tales of terror in order to understand the challenges that this type of text poses to the reader from the linguistic-discursive point of view, considering the reflections of literary studies.

KEYWORDS: Horror tale genre. Fantastic literature. Reader hesitation.

\footnotetext{
${ }^{1}$ Artigo recebido em 05 de fevereiro e aceito em 10 de abril de 2021.

2 Doutor em Estudos Linguísticos pela UFF; Professor de Linguística e Produção Textual do DLEV-UFS. Professor do mestrado PROFLETRAS-UFS. Líder do grupo de pesquisa GEADAS (Grupo de Estudos Alfabetização, Discurso e Aprendizagens). Membro do GEPLA (Grupo de Estudos e Pesquisas em Linguística Aplicada). E-mail: ricardocarvalho.ufs@hotmail.com. ORCID: https://orcid. org/0000-0001-6196-5824.
} 


\section{Introduçầo}

Os contos de terror são narrativas ficcionais que provocam a sensação do medo e estranhamento diante de experiências vividas por um personagem ou grupo de pessoas que tem a integridade física, espiritual ou psicológica ameaçada por forças sobrenaturais, delírio ou conflitos existenciais decorrente de culpa ou remorso. Essas narrativas, em muitas situações, possuem um fundo moral, visto que um personagem sofre a assombração ou comete a perseguição de outro, desrespeitando uma lei comunitária vinculada ao mundo espiritual ou social. Diferente dos contos de fadas nos quais personagens, ao final da narrativa, passam por uma metamorfose, do ponto de vista físico e social, obtendo certa promoção hierárquica; nos contos de terror observa-se o universo íntimo dos personagens invadido e desvelado, apontando para aspectos da degradação humana.

Geralmente, o autor de gênero de terror se vale de uma série de recursos discursivos para sensibilizar o leitor acerca do universo do personagem onde vive um infortúnio, permitindo ao leitor, no plano ficcional, a experiência do medo, do estranhamento e da ansiedade, a fim de oportunizar reflexões sobre a existência. O narrador dessas histórias, mas do que uma entidade ficcional que relata acontecimentos, faz avaliações e tenta persuadir o leitor a partir de um ponto de vista. Considerando os aspectos mencionados, a análise desses textos depende da observação de certas regularidades enunciativas que nos ajudam a entrar no universo discursivo dos contos de terror.

Diferente dos filmes de terror que narram por meio de imagens produzidas pelo diretor cinematográfico e a sua equipe em uma sequência textual multimodal; nos contos de terror escritos há uma exigência de mecanismos linguísticos e enunciativos promovidos pelo discurso do narrador e personagens. Destaca-se, nesse construto, o modo como o narrador organiza a projeção de enunciados ambíguos que são esclarecidos no decorrer da trama. Em muitos contos de terror, há um tom confessional, assumido por um narrador-personagem que promove um efeito de intimidade com o leitor.

Do ponto de vista estrutural, uma das propriedades do gênero conto de terror é a ocultação ou adiamento de uma informação para gerar suspense ou curiosidade diante do desfecho. 
Para garantir o suspense, é necessário um trabalho de formulação textual cuidadoso do autor, e exigir, também, do leitor o acompanhamento de pistas linguísticas e projeções enunciativas inscritas no texto. Além dos aspectos apontados, torna-se necessária a compreensão da lógica do fantástico na construção de sentido do conto de terror. As reflexões apresentadas aqui demonstram a complexidade da leitura do conto de terror, pois esse gênero procura produzir efeitos de incerteza, de estranhamento e de assombro por meio de recursos enunciativos que confluem para a literatura fantástica.

Podemos dizer que a compreensão do conto de terror, do ponto de vista linguístico-discursivo, ainda corresponde a um desafio para os estudos literários e linguísticos, visto que a apreciação do conto de terror se apoia, geralmente, em categorias construídas sob o domínio dos estudos literários (recursos estilísticos, figuras retóricas, a escolha do foco narrativo, bem como a compreensão da obra por meio da contextualização e reconhecimento de fatos no domínio da história da literatura). Sob a perspectiva de estudos linguísticos, observamos, também, categorias que exploram segmentos estruturais dos contos (tipologia narrativa, sequências textuais, macroestrutura e superestrutura textual). Em muitos momentos, as categorias mencionadas são estudadas, sem considerar o intercâmbio entre os saberes das duas áreas de conhecimento: literatura e a linguística. Neste texto, buscamos uma abordagem enunciativa voltada para regularidades dos contos de terror, pautados nos estudos de Bakhtin (2003) e Todorov (1980).

\section{Sobre a consolidaçầo do gênero contos de terror}

Sabemos que é impossível estabelecer um ponto de origem do conto de terror, todavia é razoável perceber o modo como elementos de terror se consolidam a partir das narrativas de assombração promovidas pela tradição oral em sociedades arcaicas. Nas histórias de assombração figuram personagens, situações e cenários amedrontadores. Desde obras como a Teogonia de Hesíodo e a Odisseia de Homero encontramos monstros, bruxas, seres sobrenaturais que perseguem seres humanos. Cada sociedade acaba por criar sua mitologia e suas histórias que envolvem o medo, a morte e a insegurança. 
Sendo assim, em períodos remotos, os homens contavam histórias, misturando terror e fantasia para exorcizar seus medos e anseios diante das incertezas da vida. Essas histórias alimentaram o imaginário, permitindo que o homem expusesse seus anseios na forma de fantasia. Diremos que o conto de assombração de tradição oral corresponde ao embrião dos contos de terror, seguido, então, dos romances góticos.

Do ponto de vista histórico, os contos de terror ganham força em meados do século XIX com o florescimento da imprensa e a ampliação do número de pessoas alfabetizadas. Nesse período, observa-se um forte entusiasmo pela leitura impressa, visto que a democratização da escrita às classes populares permitiu a difusão de romances, jornais e outros gêneros literários. Os contos de terror surgem no interior de revistas com o objetivo de gerar entretenimento e ao mesmo tempo explorar temas que se contrapõem às ideias do racionalismo iluminista.

O relato fantástico é um discurso coletivo e disparatado que concentra tudo aquilo que não se pode dizer na literatura oficial, a exigência de uma ordem permanente. Os temas de monstros e de outros mundos traduzem não apenas o medo e o afastamento da autoridade, mas também a fascinação que exerce e a debilidade que suscita. Desse modo, o insólito expõe a debilidade do indivíduo autônomo. A duplicidade se revela no estatuto literário já que em uma sociedade laica, liberal e não hierarquizada diferentes tipos de texto têm valor semelhante. Medos e incertezas calculadas e o desconhecido se convertem em organização lúdica. A narrativa fantástica marca o limite da leitura individual e privada e sem função coletiva explícita, reafirmando a liberdade total do imaginário. Bessière (2001) adverte que ainda para que o fantástico seja subversivo, não se deve confundir a modernidade literária e a inovação estética como portadoras de uma mudança ideológica (LIMA, 2011, p. 17).

A literatura fantástica com representação do medo aparece de forma emblemática nos romances góticos, podendo se destacar obras como $O$ Castelo de Otranto do inglês Horace Walpole (1764); Frankestein, da inglesa Mary Shelley (1816) , O médico e o monstro do escocês Robert Louis Stevenson (1885); 
Drácula (1897) do irlandês Bran Stock. Paralelo à produção de romances, encontramos narrativas mais curtas, publicadas em jornais e revistas denominadas de contos de terror. As histórias de terror vão ganhando aos pouco um caráter psicológico nas publicações impressas na medida em que são inseridas passagens do pensamento interior dos personagens por meio do discurso indireto livre. Destacam-se como precursores do gênero do conto de terror, Edgar Allan Poe (1809-1849), Howard Phillips Lovecraft (1890-1937), William Wymark Jacobs (1863-1943). Esses autores produziram contos que funcionam como matriz para a produção de novos textos da mesma espécie.

Apesar de uma gama de escritores apresentarem inúmeras possibilidades de realização do conto de terror, dizemos que o fundador desse gênero é o escritor norte-americano Edgar Allan Poe, pois além de publicar contos, assumiu o papel teorizador da construção do texto ficcional, refletindo sobre aspectos relacionados à produção de obras literárias de tal calibre que começava a ganhar projeção na década de 30 do século XIX.

As razões que levaram a Edgar Poe a assumir um papel tão importante no campo da literatura decorrem, então, de um conjunto de publicações (poemas, contos e textos de crítica literária) que promoveram rupturas com a forma de escrita de textos literários produzidos até então. Não podemos deixar de considerar na gênese de sua produção uma série de acontecimentos, em sua vida profissional, que permitiu a sedimentação de um estilo de linguagem que até os dias de hoje funciona como uma matriz para a escrita do gênero conto de terror.

Sabemos que a grande vocação de Poe foi o ofício de escritor de poesias e de contos, todavia para garantir a subsistência, o artista assumiu o papel de editor do jornal Southern Literary Messenger entre 1835-1837, disseminando muitas ideias vanguardas no âmbito da crítica literária. Já nos anos de 1837 a 1839, ocupa a função de editor assistente da revista literária Burton's Gentleman's Magazine, onde publica, contos, ensaios, resenhas literárias, textos de crítica literária, propondo reflexões teóricas que valorizavam o conto como atividade artística formulada no mesmo patamar do romance e da poesia.

Ainda no ano de 1839, Poe publica seus contos, em dois volumes, sob o título Tales of the Grotesque and Arabesque (Con- 
tos do Grotesco e do Arabesco). Este foi traduzido em 1856 por Baudelaire(1821-1867) com o título de Histórias Extraordinárias, tornando-se um livro popular por toda a Europa. No ano de 1845, publicou no jornal New York Evening Mirror o seu grande poema que marcou The Raven (O Corvo). Enquanto crítico da prosa literária, Poe ressalta a importância da formulação artística do conto em detrimento ao romance e do poema. Para o escritor, o conto tem a propriedade de revolucionar a linguagem em prosa, permitindo a exibição do talento do artista de uma forma mais nítida.

\begin{abstract}
Poe analisa uma coletânea de contos de um de seus contemporâneos, o escritor Nathaniel Hawthorne, da Nova Inglaterra, argumentando que a ficção curta seria o veículo mais apropriado para a expressão máxima dos talentos de um artista. Além disso, o autor propõe a teoria da unidade de efeito, que preconiza que uma narrativa deve ser lida de uma só assentada, do contrário "os interesses do mundo que intervêm durante as pausas da leitura modificam, desviam, anulam, em maior ou menos grau, as impressões do livro" (POE, 2004, p. 3). Ao defender esta tese, Poe se posiciona contra grande parte do fazer literário de sua época. De acordo com Robert Spiller, as opiniões sobre Poe na época romântica eram divergentes, mas preponderantemente negativas: "Tennyson o achava um gênio, e Emerson acreditava que ele era um homem da selva. Henry James pensava que o fascínio em relação à obra de Poe refletia um estado primitivo de consciência" (BELLIN, 2011, p. 43).
\end{abstract}

Poe (2001) ressalta, em sua teoria do conto, algumas características importantes para a produção de uma boa história: o domínio da brevidade, a intensidade e a unidade dramática com vista a um 'efeito único' gerador de uma sensação 'singular' como o estranhamento ou medo no conto de terror. Para o escritor, a escolha das palavras e a organização dos enunciados que estão no conto não se encontram de forma aleatória, visto que há um plano pré-estabelecido pelo autor da carpintaria textual. Dessa maneira o conto cumpre a função de criar expectativas e provocar surpresas ao leitor. Para isso, a narrativa necessita explorar a tensão entre o familiar e não familiar a quem o texto é dirigido, tanto do ponto de vista do conteúdo como da forma. 
Contribuições de Todorov para a compreensão das fronteiras do fantástico

Todorov (2006) busca compreender as facetas do modo literário fantástico, analisando um conjunto de narrativas que exploravam elementos sobrenaturais e extraordinários. O conteúdo do fantástico resulta da representação ficcional do mundo natural e do universo sobrenatural, bem como da construção do mundo ficcional maravilhoso e estranho. Por esse caminho, é possível reconhecer dois pontos extremos do fantástico: estranho puro e o maravilhoso puro.

No estranho puro, defrontamos com atitudes bizarras consideradas grandes temas de tabu social como o sadismo, o masoquismo etc. Nesse tipo de fantástico, encontramos histórias de relacionamentos incestuosos entre irmãos ou mesmo personagens que cometem atrocidades por se encontrar em estado de alucinação. O fantástico do estranho puro pode ser explicado sob a lógica do mundo natural como um acontecimento extraordinário. São atitudes recriminadas pelas instituições sociais, mas possível de serem vividas por qualquer ser humano. $O$ estranho puro pode ser compreendido como uma manifestação decorrente da explosão do inconsciente reprimida por uma lei institucional. Rezende (2006) faz o seguinte esclarecimento sobre a etimologia da palavra estranho heimlich a partir de estudos de Freud:

Em seu trabalho “O Estranho", Freud (1996b) apresenta a grande variedade de significados que a palavra "heimlich" compreende até alcançar justamente seu significado oposto. "Heimlich" originalmente significa familiar, não estranho, amistoso. De forma curiosa, "heimlich" é tão familiar e íntimo que acaba se tornando oculto. Pode-se dizer que, se alguém nutre um grande e impossível amor, este amor é "heimlich", no sentido de familiar, íntimo, pessoal, mas também existe aí um sentimento oculto, pelo fato de este amor secreto não poder ser revelado. Da mesma forma, uma casa, sendo familiar, é "heimlich" e, no entanto, também é algo íntimo, guardado e escondido. Portanto, o familiar é estranho e o estranho é familiar, ou, como diz Freud, "o estranho é aquela categoria do assustador que remete ao que é conhecido, de velho, e há muito familiar" (FREUD, 1996b, p. 238). Tudo o 
que aparentemente uma pessoa conhece de si está em nível consciente, mas também existe o que não é conhecido e que, portanto, está no inconsciente. Tudo o que aparentemente uma pessoa conhece de si está em nível consciente, mas também existe o que não é conhecido e que, portanto, está no inconsciente (REZENDE, 2006, p. 34).

Freud (2006) retoma estudos apresentados no artigo Sobre a psicologia do estranho, escrito por Ernest Jentsch em 1906. Esse defendia que a origem do sentimento de estranheza deriva da incerteza intelectual. Todo contato com aquilo que não é familiar produziria a perda de orientação perante objetos ou eventos em um determinado ambiente. Para Freud a afirmação do autor é incompleta, visto que reduz o estranhamento a uma equação 'estranho' = 'não familiar'. Freud (2006) explora o tema do 'estranho', relacionando ao que é assustador e que provoca medo e horror. Todavia, para o pesquisador, o estranho é uma categoria do assustador e do espanto que de alguma forma é explorado no âmbito do conhecido e do familiar.

Freud observa que nem toda representação exploradora do novo e do desconhecido corresponde a uma atividade assustadora. Algo novo pode se tornar estranho quando se acrescenta algo de familiar, íntimo a ponto de tocar na fragilidade humana. O familiar está naquilo que se repete e invade o universo íntimo. Nesse sentido, a palavra familiar heimlich assume a compreensão ambivalente, coincidindo com seu oposto, unheimlich. Por meio dessas observações, podemos notar que a lógica do estranho promove instabilidade diante da realidade incompreendida.

Do outro lado extremo do fantástico, encontramos a lógica do maravilhoso puro, sedimentado na imaginação e na fantasia com a finalidade de promover o espaço de fuga e a construção do mundo sobrenatural. No conto de fadas, por exemplo, vigora o onírico sem questionamentos. Nesse mundo, é possível a existência de animais que falam, abóboras que se tornam carruagens e sapos que viram príncipes, bem como vozes que saem das paredes. Diante do universo maravilhoso, tudo é admissível, sem que se obedeça a uma lógica racional.

De acordo com Todorov (1980), o universo sobrenatural na literatura realiza três funções: pragmática, semântica e sintática. 
A função pragmática tem como alvo a promoção da emoção e a manutenção do suspense no leitor em direção a um mundo imaginário. Já a função semântica no universo sobrenatural explora a autodesignação de um mundo que apresenta as suas leis próprias, possível de criação de cenário e personagens da imaginação. Diante desses aspectos é possível considerar a função sintática responsável pelo desenvolvimento estrutural da narrativa. Por meio desses aspectos, é possível considerar que a literatura pode explorar o sobrenatural, assumindo uma dimensão social capaz de romper com as leis racionais e institucionais, tocando em áreas inacessíveis da vida humana que não se explicam por uma exposição lógica evidenciada no mundo ordinário. (TODOROV, 1980, p. 171).

Ultrapassando o fantástico maravilhoso, encontramos as narrativas de ficção científica que apresentam formulações possíveis de existência no mundo futuro, todavia sua existência se encontra no plano das hipóteses sustentáveis com base no conhecimento científico. Com esses dois mundos discursivos do estranho (pautado no extraordinário) e do maravilhoso (pautado no sobrenatural), podemos chegar ao fantástico estranho e ao fantástico maravilhoso.

Quadro 1 : fronteiras do fantástico constitutivas do conto de terror segundo Todorov

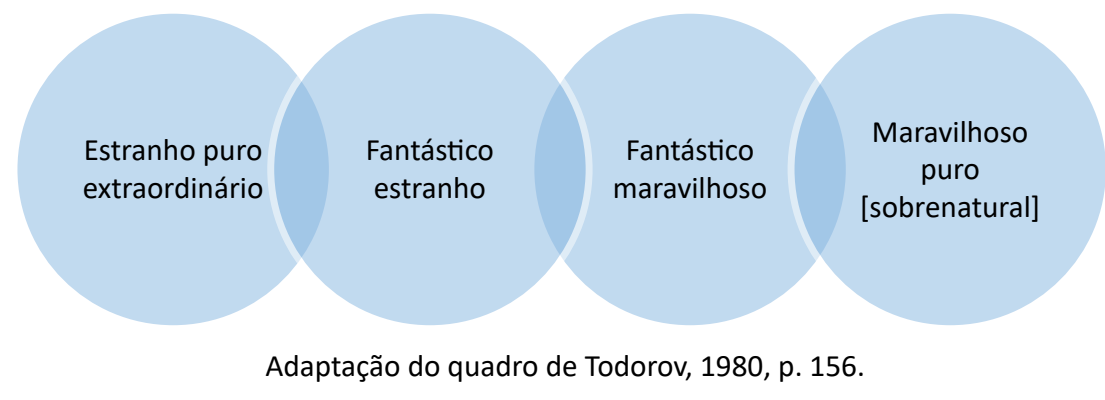

O fantástico, reconhecido no conto de terror, implica a construção de um mundo ficcional híbrido, dispondo sempre de um modo enunciativo que apresenta tensão entre dois mundos (extraordinário e sobrenatural), gerando, assim, uma sensação de dúvida no leitor sobre a possibilidade dos fatos narrados existirem no mundo ordinário, levando o leitor a desconfiar das coincidências das razões dos fenômenos misteriosos ocorridos e do comportamento do narrador que compartilha informações. Diante 
dos fatos aqui descritos, advertimos que no conto de terror pode-se observar um leitor oscilante diante de episódios com aparência sobrenatural. É o caso do conto "O gato preto" de Poe no qual o protagonista, influenciado pela bebida, percebe a presença de uma silhueta no formato de gato em uma parede depois de matar um animal da espécie. Verifica-se, nesta narrativa, a existência de elementos promotores de hesitação entre acontecimentos que parecem sobrenaturais e extraordinários ao mesmo tempo.

O conto "gato preto" suscita outro aspecto utilizado na literatura fantástica que é a visão de dupla identidade de um personagem. Para projetar esse efeito, Poe escolhe em si a figura do gato que possui contorno místico, apontando para o universo mágico e sobrenatural do animal ressaltado por antigas civilizações e diferentes culturas. Sobre a figura do gato, descreve-se:

No dicionário dos símbolos (1990), o gato preto pode ser relacionado a diferentes significados, entre um ser sagrado e místico. No antigo Egito o gato era visto como um ser sagrado da deusa Bastet, que era representada com o corpo humano e a cabeça de um gato. Quando a deusa Bastet se enfurecia para defender seus filhos tornava-se uma leoa; quando calma, voltava a ser uma gata. Por isso, para os egípcios, o gato é símbolo da docilidade: em função da extrema maternidade da referida deusa. Já na cultura japonesa, na latina e em grande parte das culturas, inclusive na nossa, a visão de um gato é sinal de mau agouro (PEREIRA; GAMA-KHALIL, 2008, p.10).

É bastante relevante no enredo da história do fantástico puro a representação de personagens ambíguos que deixa o leitor em estado de hesitação. Podemos reconhecer nos contos de terror acontecimentos pouco comuns ao mundo ordinário, mas possíveis de existir, caracterizando, assim, uma dimensão fantástica.

Nesse contexto, Todorov chama atenção para a inviabilidade configurar os contos do fantástico puro a uma leitura "poética" ou "alegórica", haja vista o propósito comunicativo não ser o de explorar um sentido metafórico e um sentido literal para a leitura dessas narrativas. Os personagens e as ações não assumem uma forma alegórica para falar de uma realidade abstrata, mas representam situações psicológicas exploradoras dos limites da alma humana. 


\title{
A construçăo enunciativa do modo literário fantástico
}

Nos contos fantásticos vigoram relatos imprecisos, insólitos e ambíguos que não configuram a intenção de fugir do sentido literal. Ao terminar uma leitura de conto inscrito nesse modo literário, o leitor se sente impactado e estupefato diante das tensões exploradas na trama. Do ponto de vista da evolução do fantástico na literatura, Correia (2011) faz o seguinte comentário:

\begin{abstract}
a narrativa fantástica, ao invés de apresentar mundos novos, dissociados da realidade, faz uso da vida cotidiana, apresentando sua problemática através da abordagem do comportamento humano. (...) Inicialmente, no século XVIII, o insólito era produzido no nível semântico; entre os séculos XVIII e XIX, exigia a presença de um elemento sobrenatural, sendo que o medo era provocado a partir da figura de um monstro ou um fantasma, demonstrando que a angústia sempre habitava o ambiente externo; no século XIX, a dimensão psicológica das personagens passou a ser mais explorada e o sobrenatural foi substituído por imagens assustadoras advindas da loucura, de alucinações ou pesadelos, sendo que a angústia habitava o interior do próprio sujeito e, finalmente, no século $X X$, o fantástico infiltrou-se no nível sintático, criando incoerências entre elementos da vida comum, com a angústia frente ao surgimento do absurdo (CORREA, 2011, p. 66-67).
\end{abstract}

O insólito e o acontecimento estranho podem promover hesitação, levando o leitor a questionar as possibilidades de sua existência. Dessa forma, para o fio do discurso se projetar de forma tensa, o autor do conto de terror constrói um narrador que realiza descrições imprecisas, podendo caminhar em direção ao sonho, ao delírio e ao mistério para promover uma atmosfera de ação sobrenatural. A marca do fantástico encontra-se no obscuro, na incerteza, na fantasia, na imaginação e representações expressivas advindas do inconsciente dos personagens. Todos estes elementos nos levam à representação de fatos sobrenaturais que parecem ultrapassar a barreira do possível no plano do mundo ordinário, todavia no decorrer do conto de terror é possível reconhecer fatos e explicações no corpo de texto que descontroem a visão de um possível acontecimento sobre-humano. Souza (2011) 
sintetiza a caracterização de Cesarini (2006) sobre os aspectos retóricos do fantástico responsáveis pela construção dos efeitos produzidos pelo conto de terror:

1) posição de relevo dos procedimentos narrativos no próprio corpo da narração; 2) a narração em primeira pessoa; 3) um forte interesse pela capacidade projetiva e criativa da linguagem; 4) envolvimento do leitor: surpresa, terror, humor; 5 ) passagem de limite e de fronteira; 6) o objeto mediador; 7) as elipses; 8) a teatralidade; 9 ) a figuratividade; 10 ) o detalhe. Ceserani (2006) ainda elenca sistemas temáticos recorrentes na literatura fantástica: 1) a noite, a escuridão, o mundo obscuro e as almas do outro mundo; 2) a vida dos mortos; 3) o indivíduo, sujeito forte da modernidade; 4) a loucura; 5) o duplo; 6) a aparição do estranho, do monstruoso, do irreconhecível; 7) o Eros e a frustração do amor romântico; 8) o nada (SOUZA, 2011, p. 8).

Os personagens e a atmosfera dos contos de terror são vitalizados por meio de elementos fantásticos. Percebe-se a presença de deformidades físicas ou psicológicas, acontecimentos extraordinários sobre os quais o leitor hesita sobre a possibilidade de sua existência ou se assusta diante dos sortilégios de uma vida humana. Dentro da categoria dos textos fantásticos, os contos de terror são narrativas ficcionais provocadoras da sensação do medo e do estranhamento diante de experiências de um personagem que tem a sua integridade física, espiritual ou psicológica em desiquilíbrio. Essas narrativas, normalmente, têm um fundo moral, pois os protagonistas sofrem angústia ou perseguições em decorrência das ações cometidas no passado que romperam com alguma regra social.

No domínio do fantástico, o narrador se desdobra em ator, relator e testemunha que se indaga sobre os fatos ocorridos. $\mathrm{O}$ narrador-herói está implicado na encenação das ações do enredo, assume o discurso em primeira pessoa e coloca em jogo a paixão acima da razão ao relatar os fatos. Por outro lado, existe a figura do narrador que pode assumir o papel de testemunha lúcida, indagando-se sobre os fatos narrados e comentando com o leitor as suas impressões sobre o que se narra. No conto fantástico ocorre, assim, um desdobramento do foco narrativo que o difere 
do modo narrativo de em um conto maravilhoso tradicional ou uma história que evoca o estranho puro para impressionar como demonstra Camarani.

No maravilhoso encontra-se o que Todorov denomina "a não-representação do narrador", na qual se presume que os acontecimentos se contam por si mesmos: trata-se do modelo clássico do "Era uma vez...". No caso do fantástico, opostamente, os narradores são preferencialmente representados. A partir de Todorov, Bellemin-Noël mostra que a "visão de dentro" e a "visão com" nunca são separadas de maneira nítida; quando em uma obra fantástica se encontram de um lado um relator, de outro um ator, os dois não são senão hipóstases de uma única e mesma figura, o narrador protagonista. $O$ esquema de organização é o de uma narrativa desdobrada: há o "je", a testemunha lúcida, que se interroga na incerteza, e há o "moi", o herói que vive a aventura com paixão (até a morte ou a loucura, na maioria dos casos); o ponto de vista é eminentemente pessoal (CAMARANI, 2014, p. 76).

Camarani (2014) ainda afirma que a ficção científica, ao contrário do conto de fadas, possui um narrador que assume um ponto de vista impessoal. Tomando como ponto de partida as reflexões Todorov (1980) sobre a "representação do narrador", no texto de ficção científica busca-se produzir o efeito de objetividade; instalando um narrador-testemunha que assume o papel de redator imaginário de um possível relatório científico. Nesse gênero, o redator apresenta domínio de conhecimentos enciclopédicos e realiza uma exposição na qual vigora o didatismo capaz de descrever de forma detalhada a exploração de um planeta, sutilezas de uma expedição marítima ou elementos envolvidos em uma experiência científica com base nos parâmetros do mundo ordinário.

Quanto ao tipo de narração do ponto de vista cronológico, Camarani (2014) explica que existem diferenças entre o conto fantástico e o conto maravilhoso. Neste último, existe uma voz narrativa em off que não estabelece uma ruptura entre os acontecimentos relatados em uma sucessão cronológica, fazendo fluir as sequências narrativas. A autora afirma, ainda, que há uma voz homogênea do ponto de vista e do modo como se distribui o tem- 
po na linguagem tradicional do maravilhoso. Em oposição a este modo de narrar, observa-se no narrador do conto fantástico uma cisão que justapõe e promove a mistura de duas vozes ou mais. Percebe-se a presença de um narrador-testemunha que dialoga com o leitor e pode ceder a palavra ao herói-narrador por meio de artifícios formais como a exposição de uma confissão ou mesmo a descoberta de documentos pessoais. Todorov (1980) apresenta argumentos que explicam o movimento polifônico do conto fantástico que faz o leitor a hesitar diante das informações emitidas pelo narrador enquanto personagem envolvido na trama. Ele afirma que o leitor não tem total certeza quanto à interpretação dos fatos narrados por conta da forma de realização dos mecanismos linguísticos e a incongruência das afirmações enunciadas.

A ambiguidade do ponto de vista enunciativo é causada, em muitos momentos, por marcas linguísticas que envolvem o emprego dos tempos verbais no pretérito imperfeito, locuções introdutivas, bem como o uso de certos modalizadores de dúvida. Todorov (1980, p.53) exemplifica por meio da comparação de duas frases retirada do romance de Gerard Nerval intitulado "Aurélia" em que é apresentado um narrador nos limites da loucura. O sujeito da enunciação se divide, apresentando enunciados que parecem se contradizer, como "Chove lá fora" e "Talvez chova lá fora". Os dois enunciados se referem ao mesmo fato; todavia o primeiro retrata uma certeza e o segundo uma incerteza. Esse fenômeno pode ser explicado por meio da observação das diferentes vozes que enunciam os fatos e acontecimentos de forma modalizada.

Neste contexto, o grau de precisão de um enunciado pode ser observado pelo uso dos verbos. Para Todorov, o pretérito imperfeito pode representar um sentido temporal vago quando se diz, por exemplo, "Eu amava Aurélia", visto que não é possível afirmar com precisão a duração do ato descrito, isto é, não sabemos se o sujeito ainda ama ou deixou de amar, referindo-se a um passado totalmente acabado ou ainda por se concluir. Pelo fato de estar no passado, é mais provável que a ação tenha cessado, contudo o uso de pretérito imperfeito pode representar continuidade da ação até o momento atual da enunciação.

Todorov (1980) demonstra que nos contos fantásticos é bastante comum a utilização do verbo no imperfeito para promover imprecisões, além do uso de verbos ou locuções verbais que 
figuram a percepção de maneira vaga (acreditar, ter a impressão, confiar por um momento, sentir-se levado, assemelhar-se, parecer). Os verbos que o narrador deixa em seu discurso podem suspender informações que, em um momento posterior, serão reveladas. Para Todorov, se as locuções declarantes de incerteza estivessem ausentes, o leitor mergulharia no mundo do maraviIhoso, visto que os dados se remeteriam para uma esfera para além do mundo ordinário, sem referência à realidade cotidiana. Por meio do uso do pretérito imperfeito, é possível introduzir um distanciamento entre os personagens e o narrador, marcando o posicionamento deste último do ponto de vista enunciativo.

\section{Consideraçồes sobre procedimentos interacionais na sala de aula}

Para realizar propostas de leitura com gênero conto de terror não contamos apenas como os elementos inscritos no texto, mas com uma série de elementos contextuais que direcionam a produção de sentido do texto. Desta forma, é importante levar em conta os parâmetros contextuais que promovem a interação verbal e a atualização dos sentidos da leitura no plano interdiscursivo.

Além dos aspectos apontados, destacamos a compreensão do processo que ocorre na produção de um conto de terror sob a lógica do fantástico para poder perceber os seus efeitos de sentido. Segundo Furtado (1980), o processo de produção de sentidos, que envolve sujeitos enunciativos na literatura fantástica, depende das seguintes atividades:

1. Instaurar um narratário (preferencialmente intradiegético), ao qual cabe, em princípio, uma dupla função: por um lado, sentir e refletir a leitura incerta da manifestação meta-empírica, construindo e condensando a necessária hesitação; por outro, transmitir ao receptor real do enunciado idêntica perplexidade perante o conteúdo da intriga, ou seja, contaminar o leitor com sua hesitação; 2 . Apresentar personagens que assumam para si a identificação acima referida e que a suscitem por parte do leitor, representando, simultaneamente, através de si, a percepção ambígua das ocorrências com as quais são confrontadas e a consequente indefinição perante o sobrenatural, o 
insólito; 3. Organizar as funções das personagens de acordo com uma estrutura actancial que reflita e confirme as características essenciais ao gênero já apresentadas; 4. Utilizar narradores intradiegéticos - auto ou homo -, cujo duplo estatuto face à intriga resulte em uma maior autoridade perante o receptor real da enunciação, o leitor, e na capacidade de o compelir a uma mais estreita aquiescência em relação aquilo que é narrado, independentemente de seu aporte natural, estranho, insólito ou não; 5 . Evocar um espaço híbrido, indefinido, que, aparentando sobretudo representar o mundo real, referencial e exterior à narrativa, o universo do leitor, contenha indícios da própria subversão deste e a deixe insinuar-se aos poucos (FURTADO, 1980, p. 133-134).

As reflexões que apresentamos até aqui demonstram a complexidade da leitura e a produção de contos de terror, quando o autor produz efeitos da incerteza, do estranhamento e de medo por meio de recursos enunciativos vinculados ao modo literário fantástico. É por meio da observação da tensão entre o extraordinário e do sobrenatural, da tensão entre as vozes que narram, do uso de modalizadores que provocam incertezas para que o leitor vivencie o processo de fruição. Destacamos a importância de atividades metanarrativas que analisam as formulações responsáveis pela construção do universo psicológico do narrador, exprimindo sensações que delineiam a dinâmica enunciativa com base em um interlocutor implícito (narratário). Os dados dessa pesquisa correspondem a um pontapé inicial para a elaboração de propostas de leitura, apresentando elementos importantes que precisam ser levados em conta para a formação de leitor do gênero conto de terror.

\section{Referências}

BAKHTIN, M. M; VOLOCHÍNOV, V. N. Estética da criação verbal. São Paulo: Martins Fontes, 2003.

BELLIN, G. P. Edgar Allan Poe e o surgimento do conto enquanto gênero de ficção. Universidade Federal do Paraná. Anuário de Literatura, v. 16, n. 2, p. 41-53, 2011. 
CAMARANI, A. L. S. A literatura fantástica: caminhos teóricos. São Paulo, Cultura Acadêmica (Coleção Letras, 9), 2014.

CESERANI, R. O fantástico. Trad. Nilton Cezar Tridapalli. Curitiba: Ed. UFPR, 2006.

CORRÊA, L. C. O fantástico e o estranho em O coração denunciador, de Edgar Allan Poe. Revista Pandora, v. 6, p. 65-78, 2011.

FURTADO, F. A Construção do Fantástico na Narrativa. Livros Horizonte, Lisboa, 1980.

FREUD, S. O estranho. In: FREUD, S. Obras psicológicas completas de Sigmund Freud: edição standard brasileira. Trad. Themira de Oliveira Brito, Paulo Henrique Britto, Christiano Monteiro Oiticica. Rio de Janeiro: Imago, 1996.

PEREIRA, A. B.; GAMA-KHALIL, M. M. O espaço e o fantástico na obra de Edgar Allan Poe. Revista Horizonte Científico, v. 2, n. 2, 2008. Disponível em: http:// www.seer.ufu.br/index.php/horizontecientifico/article/view/4025/3001. Acesso em 4 de jun. 2017.

REZENDE, M. L. F. Edgar Allan Poe, o estranho que escreveu sua vida em contos de terror. 2006. Monografia (Conclusão em Letras). Centro Universitário de Itajubá. Itajubá, 2006.

SOUZA, V. M. C. de. O fantástico em Machado de Assis: "Entre santos". Revista Pandora Brasil. Edição especial n. 6, maio 2011.

TODOROV, T. Introdução à narrativa fantástica. Trad. CASTELLO, Maria Clara Correa. São Paulo: Perspectiva, ano 1980. 